\begin{tabular}{|c|c|}
\hline Title & Reduced thermal resistance in A IGaN/GaN multi-mesa channel high electron mobility transistors \\
\hline Author(s) & A subar, Joel T.; Y atabe, Zenji; Hashizume, T amotsu \\
\hline Citation & $\begin{array}{l}\text { A pplied Physics Letters, 105(5), } 53510 \\
\text { https://doi.org/10.1063/1.4892538 }\end{array}$ \\
\hline Issue Date & $2014-08-04$ \\
\hline Doc URL & http:/hdl.handle.net/2115/57547 \\
\hline Rights & $\begin{array}{l}\text { Copyright } 2014 \text { A merican Institute of Phy sics. This article may be downloaded for personal use only. A ny other use } \\
\text { requires prior permission of the author and the A merican Institute of Physics. The following article appeared in A pplied } \\
\text { Physics Letters 105, } 053510 \text { (2014); doi: } 10.1063 / 1.4892538 \text { and may be found at http://dx.doi.org/10.1063/1.4892538. }\end{array}$ \\
\hline Type & article \\
\hline File Information & 1.4892538.pdf \\
\hline
\end{tabular}

Instructions for use 


\section{AIP / Apolied Pyysics \\ Letters}

\section{Reduced thermal resistance in AIGaN/GaN multi-mesa-channel high electron mobility transistors}

Joel T. Asubar, Zenji Yatabe, and Tamotsu Hashizume

Citation: Applied Physics Letters 105, 053510 (2014); doi: 10.1063/1.4892538

View online: http://dx.doi.org/10.1063/1.4892538

View Table of Contents: http://scitation.aip.org/content/aip/journal/apl/105/5?ver=pdfcov

Published by the AIP Publishing

\section{Articles you may be interested in}

Effect of proton irradiation on thermal resistance and breakdown voltage of InAIN/GaN high electron mobility transistors

J. Vac. Sci. Technol. B 32, 051203 (2014); 10.1116/1.4891629

Probing channel temperature profiles in AlxGa1-xN/GaN high electron mobility transistors on 200mm diameter $\mathrm{Si}(111)$ by optical spectroscopy

Appl. Phys. Lett. 105, 073504 (2014); 10.1063/1.4893603

AlGaN/GaN high-electron mobility transistors with low thermal resistance grown on single-crystal diamond (111) substrates by metalorganic vapor-phase epitaxy

Appl. Phys. Lett. 98, 162112 (2011); 10.1063/1.3574531

Finite-element simulations of the effect of device design on channel temperature for $\mathrm{AlGaN} / \mathrm{GaN}$ high electron mobility transistors

J. Vac. Sci. Technol. B 29, 020603 (2011); 10.1116/1.3567183

Surface strain and its impact on the electrical resistivity of GaN channel in AIGaN/GaN high electron mobility transistor

Appl. Phys. Lett. 93, 222106 (2008); 10.1063/1.3040315

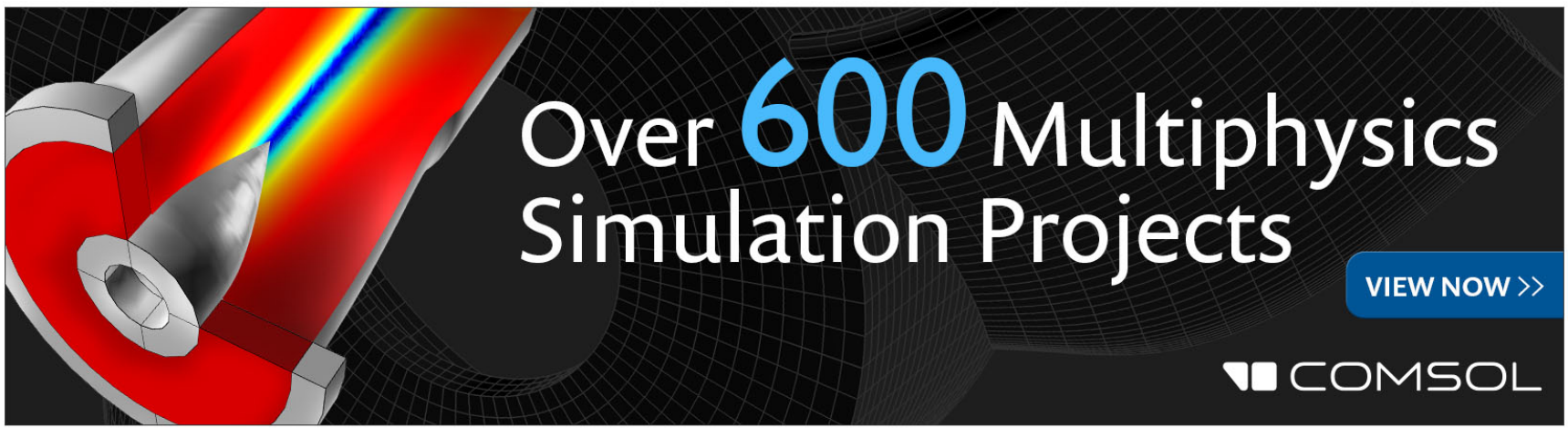




\title{
Reduced thermal resistance in AIGaN/GaN multi-mesa-channel high electron mobility transistors
}

\author{
Joel T. Asubar, ${ }^{1,2, a)}$ Zenji Yatabe, ${ }^{1,2}$ and Tamotsu Hashizume ${ }^{1,2}$ \\ ${ }^{1}$ Research Center for Integrated Quantum Electronics (RCIQE) and Graduate School of Information Science \\ and Technology, Hokkaido University, Sapporo, Japan \\ ${ }^{2}$ Japan Science and Technology Agency (JST), CREST, 102-0075 Tokyo, Japan
}

(Received 26 May 2014; accepted 26 July 2014; published online 7 August 2014)

\begin{abstract}
Dramatic reduction of thermal resistance was achieved in AlGaN/GaN Multi-Mesa-Channel (MMC) high electron mobility transistors (HEMTs) on sapphire substrates. Compared with the conventional planar device, the MMC HEMT exhibits much less negative slope of the $I_{D^{-}} V_{D S}$ curves at high $V_{D S}$ regime, indicating less self-heating. Using a method proposed by Menozzi and co-workers, we obtained a thermal resistance of $4.8 \mathrm{~K}-\mathrm{mm} / \mathrm{W}$ at ambient temperature of $\sim 350 \mathrm{~K}$ and power dissipation of $\sim 9 \mathrm{~W} / \mathrm{mm}$. This value compares well to $4.1 \mathrm{~K}-\mathrm{mm} / \mathrm{W}$, which is the thermal resistance of AlGaN/GaN HEMTs on expensive single crystal diamond substrates and the lowest reported value in literature. (C) 2014 AIP Publishing LLC. [http://dx.doi.org/10.1063/1.4892538]
\end{abstract}

Gallium Nitride $(\mathrm{GaN})$ is considered as one of the leading material candidates for realizing next-generation electronics devices capable of handling unprecedented power levels. ${ }^{1}$ However, due to thermal limitation of conventionally used substrate materials, usable power densities are limited to $5-8 \mathrm{~W} / \mathrm{mm} .^{2}$ At high power dissipation, the problem of selfheating, which is usually manifested as a negative slope of the $I_{D}-V_{D S}$ curves at high $V_{D S}$ regime, becomes critical, especially on devices fabricated on the common but thermally resistive sapphire substrates. ${ }^{3-5}$ Self-heating leads to increased channel temperature which not only reduces the electron mobility and saturation velocity ${ }^{6}$ but also decreases the median time to failure of power devices. ${ }^{7}$ Moreover, selfheating may lead to a thermally-induced breakdown at voltage levels lower than the theoretically predicted value. ${ }^{8}$ Since it is widely believed that the generated Joule heat mainly dissipates through the substrate, the obvious solution is to use low thermal resistivity but expensive substrates such as $\mathrm{SiC}{ }^{9}$ and GaN. ${ }^{10}$ Recently, Hirama and co-workers have reported a thermal resistance record value of $4.1 \mathrm{~K}-\mathrm{mm} / \mathrm{W}$ for an AlGaN/GaN HEMT fabricated on single-crystal diamond. ${ }^{11}$ Riedel et al. were able to further reduce the thermal resistance of $\mathrm{AlGaN} / \mathrm{GaN}$ HEMTs on $\mathrm{SiC}$ using a hot-wall metal organic chemical vapor deposition (MOCVD) grown aluminum nitride (AIN) nucleation layer, which lowers the thermal-boundary resistance between $\mathrm{GaN}$ and $\mathrm{SiC}^{12}$ Selfheating had also been addressed using heat spreading layers such as thick AlN surface passivation films. ${ }^{13}$ Using flexible graphene quilts precisely transferred over the drain contacts, Yan et al. demonstrated lowering the hotspot temperature by as much as $20^{\circ} \mathrm{C} .{ }^{14}$ Various flip-chip bonding techniques have also been shown to be effective in improving thermal performance of AlGaN/GaN HEMTs. ${ }^{15,16}$ In this Letter, we report dramatic reduction of thermal resistance in AlGaN/ GaN MMC HEMTs fabricated on sapphire substrates. Our structure-based approach offers an alternative avenue in mitigating self-heating problems in AlGaN/GaN HEMTs. Using

\footnotetext{
${ }^{\text {a)} E-m a i l: ~ j o e l @ r c i q e . h o k u d a i . a c . j p ~}$
}

a technique proposed by Menozzi and co-workers, ${ }^{17}$ we extracted the thermal resistance of the MMC and compared it with that of the conventional planar device fabricated on the same chip.

The AlGaN/GaN MMC HEMT is schematically illustrated in Fig. 1. The parallel nano-channels structure facilitates the modulation of the two-dimensional electron gas (2DEG) vertically from the top and laterally through the sidewalls, improving gate controllability and shifting the threshold voltage $V_{T H}$ towards the normally-OFF voltage direction. ${ }^{18}$ Moreover, due to the resulting nano-channel high impedance, the MMC HEMT is less sensitive to changes in the access region; may they be due to trapping or changes in the physical dimension like gate-drain (G-D) spacing $L_{G D}$, providing better current stability and breakdown voltage design flexibility compared with the planar HEMT. ${ }^{18-20}$ Very recently, several groups have reported improved performance from nitride-based devices with very similar structure. Lee et al. have demonstrated nanowire channel InAlN/GaN HEMTs with high linearity of both transconductance $g_{m}$ and cut-off frequency $f_{t}{ }^{21}$ Simin et al. have demonstrated in their perforated-channel AlGaN/GaN HEMTs significant reduction

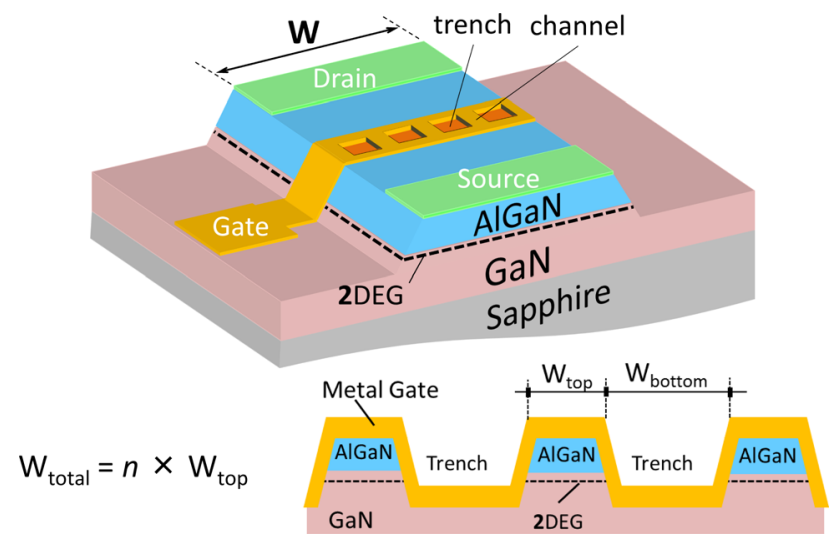

FIG. 1. Schematic illustration of the AlGaN/GaN MMC HEMT. The total effective gate width $W_{\text {total }}$ is equal to $n \times W_{\text {top }}$, where $n$ is the number of mesa-channels and $W_{\text {top }}$ is the width of each mesa-channel. 
of on-resistance-gate capacitance $\left(R_{O N} C_{G}\right)$ product, significantly improving the transistor operation in power switches and amplifiers. ${ }^{22}$

The $\mathrm{Al}_{0.23} \mathrm{Ga}_{0.77} \mathrm{~N} / \mathrm{GaN}$ heterostructure used in the present study was grown by MOCVD technique on (0001) sapphire substrates. The thickness of the AlGaN barrier layer is $25 \mathrm{~nm}$. The typical values of 2DEG sheet density and mobility at room temperature (RT) are $9.0 \times 10^{12} \mathrm{~cm}^{-2}$ and $1330 \mathrm{~cm}^{2} / \mathrm{Vs}$, respectively. The fabrication process is similar to that discussed in Ref. 20. To extract the thermal resistance $\left(R_{T H}\right)$ of the devices, we applied the technique proposed by Menozzi and co-workers, ${ }^{17}$ which only requires measurement of DC $I_{D}-V_{D S}$ curves at different ambient temperature $T_{A}$. Thus, with the exception of an accurate and stable temperature controller, this technique requires very standard and relatively inexpensive experimental set-up. This method assumes a linear dependence of saturation drain current $I_{D}$ on channel temperature $T_{C}$ once the linear dependence of $I_{D}$ on ambient temperature $T_{A}$ is established. In principle, it is possible to limit the temperature range so that $I_{D}$ varies with $T_{A}$ linearly. ${ }^{17,23}$ Indeed, the linear relationship of AlGaN/ GaN HEMTs $I_{D}$ and $T_{A}$ has been verified experimentally by several research groups. ${ }^{14,24,25}$ Aside from choosing a suitably narrow intervals of $T_{A}$ and power dissipation $P_{D}$, wherein the $I_{D}$ dependence on $T_{A}$ can be linearized with accuracy and $R_{T H}$ can be considered constant, no other simplifying assumption is necessary. ${ }^{17}$ The physical basis of this method is discussed below.

In analogy to electrical resistance, the thermal resistance $R_{T H}$ (Ref. 17) can be given by

$$
R_{T H}=\frac{\Delta T}{P_{D}}=\frac{T_{C}-T_{A}}{V_{D S} \times I_{D}}=\frac{T_{C 0}-T_{A 0}}{V_{D S} \times I_{D 0}} .
$$

Here, $\Delta T$ is the difference between the device channel temperature $T_{C}$ and ambient temperature $T_{A}, P_{D}$ is the device power dissipation which is the product of a fixed drain to source voltage $V_{D S}$ and saturation drain current $I_{D}$. At a reference ambient temperature $T_{A 0}$, at the same $V_{D S}$, the corresponding values of channel temperature, and drain current are $T_{C O}$ and $I_{D O}$, respectively. Assuming linear relationship of $I_{D}$ and temperature, then

$$
I_{D}=I_{D 0}+h\left(T_{A}-T_{A 0}\right)
$$

and

$$
I_{D}=I_{D 0}+h^{\prime}\left(T_{C}-T_{C 0}\right),
$$

where, $h$ and $h^{\prime}$ are proportionality constants. Substituting Eqs. (2) and (3) to (1) and simplifying, it easy to obtain the following relationship:

$$
\frac{1}{h}=\frac{1}{h^{\prime}}-R_{T H} V_{D S}
$$

Thus, $R_{T H}$ is the slope of the variation of $1 / h$ with $V_{D S}$. Figure 2 summarizes further in a flowchart the $R_{T H}$ extraction method.

Figures 3(a), inset of 3(b), and 3(b) show the $T_{A}$ dependence of $I_{D}-V_{D S}$ curves, $V_{D S}$ dependence of $I_{D^{-}} T_{A}$ plots, and the $1 / h-V_{D S}$ plot, respectively, of the planar device while

\section{(1) Measure $I_{D}\left(V_{D S}\right) @$ an arbitrary appropriate $\mathrm{V}_{\mathrm{GS}}$ at different $\mathrm{T}_{\mathrm{A}}$ \\ (2) At constant $V_{D S}$, plot $I_{D}\left(T_{A}\right)$}

Solve the slope $h$ and repeat for several $\mathrm{V}_{\mathrm{DS}}$

(3) Plot $1 / h\left(V_{D S}\right)$

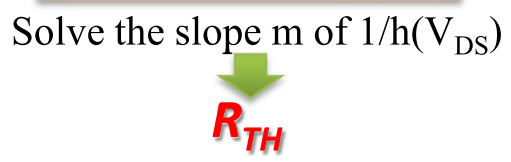

FIG. 2. Simplified flowchart of the thermal resistance $R_{T H}$ extraction from the $I_{D}-V_{D S}-T_{A}$ plots proposed by Menozzi et al. ${ }^{17}$

Figure 4 shows the same set of data for the MMC device having same levels of raw $I_{D}$. The DC $I_{D}-V_{D S}$ characteristics were measured using an Agilent B1500A semiconductor device parameter analyzer while the ambient-chuck temperature was precisely controlled by a Vector Semiconductor THC-151 thermocontroller. A starting temperature of $42^{\circ} \mathrm{C}$ was chosen because it is the lowest temperature closest to RT that can be controlled in the present experimental setup. Both devices investigated have gate lengths $L_{G}$ of $1 \mu \mathrm{m}$, gate-drain spacing $L_{G D}$ of $10 \mu \mathrm{m}$, and gate-source spacing
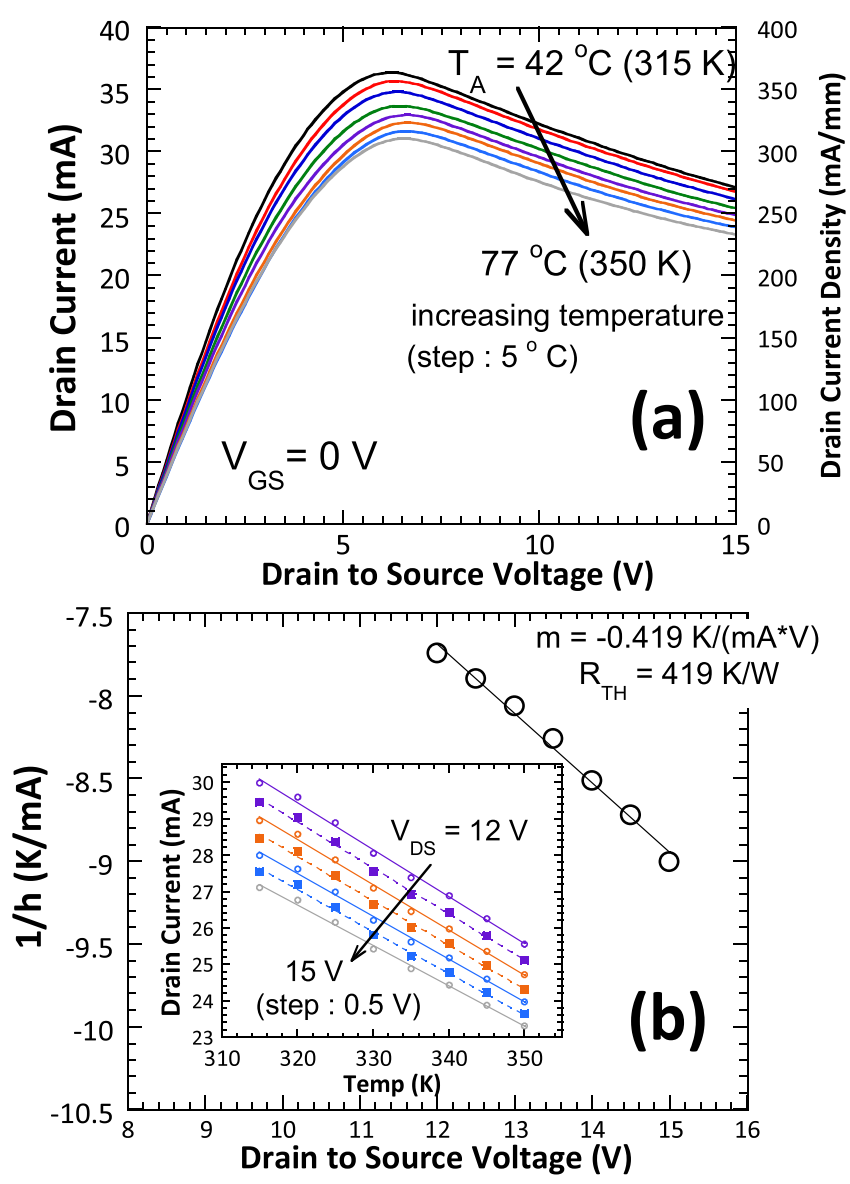

FIG. 3. Planar device with $W$ of $100 \mu \mathrm{m}$ (a) $T_{A}$ dependence of $I_{D}-V_{D S}$ curves, ((b), inset) $V_{D S}$ dependence of $I_{D}-T_{A}$ plots, (b) $1 / h-V_{D S}$ plot. 

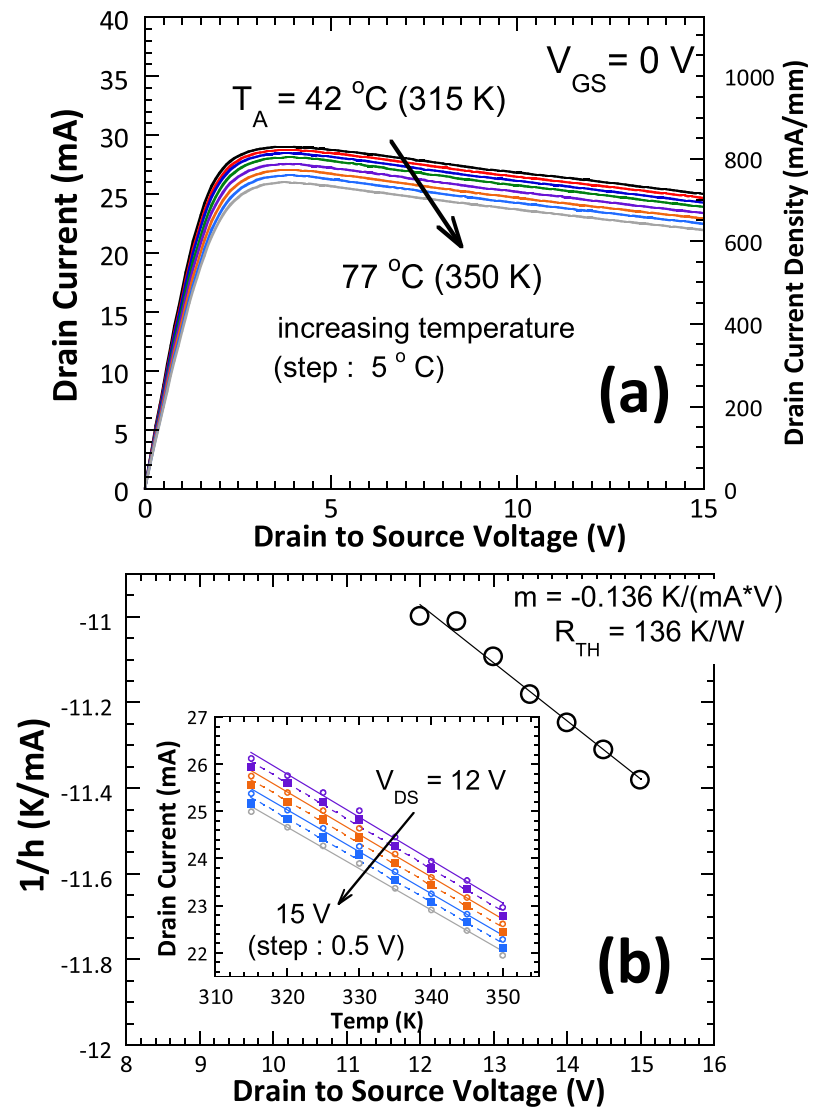

FIG. 4. MMC device with $W_{\text {top }}$ of $70 \mathrm{~nm}$ and $W_{\text {total }}$ of $35 \mu \mathrm{m}$ (a) $T_{A}$ dependence of $I_{D^{-}} V_{D S}$ curves, ((b), inset) $V_{D S}$ dependence of $I_{D}-T_{A}$ plots, (b) $1 / h-V_{D S}$ plot.

$L_{G S}$ of $2 \mu \mathrm{m}$. The planar device has a gate width $W$ of $100 \mu \mathrm{m}$. Scanning electron microscopy investigations revealed that the MMC device has a $W_{\text {top }}$ of $\sim 70 \mathrm{~nm}$. Since there are 500 periods of mesa-trench structures within the gate electrode width of $200 \mu \mathrm{m}$, the effective total gate width $W_{\text {total }}$ is $35 \mu \mathrm{m}$ for the MMC device. The threshold voltage $V_{T H}$ values are $-1.8 \mathrm{~V}$ and $-3.7 \mathrm{~V}$ for the $\mathrm{MMC}$ and planar devices, respectively. The MMC device showed significantly less knee voltage $V_{\text {knee }}$ consistent with our previous reports. ${ }^{18-20}$ Even though its effective gate width $W_{\text {total }}$ is just almost a third of that of the planar device, the MMC device exhibited almost the same levels of raw $I_{D}$. At $T_{A}$ of $42^{\circ} \mathrm{C}, V_{G S}=0 \mathrm{~V}$, and $V_{D S}=15 \mathrm{~V}$, the MMC and planar devices have raw $I_{D}$ of $\sim 25 \mathrm{~mA}$ and $\sim 27 \mathrm{~mA}$, respectively. Solving for the drain current density $I_{D S \text { den }}$ (raw $I_{D}$ divided by the effective gate width $W_{\text {total }}$ ), the above values translate to $714 \mathrm{~mA} / \mathrm{mm}$ and $270 \mathrm{~mA} / \mathrm{mm}$, respectively for the MMC and planar devices. As can be seen in Fig. 3(a), the planar device suffers from severe self-heating as indicated by the steep negative slope of the $I_{D}-V_{D S}$ curves at high $V_{D S}$ range. On the other hand, even though its current density is more than twice that of the planar, the MMC device exhibited less negative slope of the $I_{D}-V_{D S}$ curves suggesting weaker selfheating.

The insets in Figures 3(b) and 4(b) show $T_{A}$ dependence of $I_{D}$ at different values of $V_{D S}$ ranging from 12 to $15 \mathrm{~V}$ of the planar and MMC devices, respectively. This suitably narrow range of $V_{D S}$ was chosen to keep the $R_{T H}$ essentially constant as mentioned above. The insets reveal well-behaved linear variation of $I_{D}$ with $T_{A}$ for different values of $V_{D S}$, verifying the $I_{D}-T_{A}$ linear relationship assumption rendering the method of Menozzi et al. applicable. ${ }^{17}$ Following step (2) in Fig. 2, from the best fit lines, the values of the slope $h$ for each $V_{D S}$ were then determined. Figures 3(b) and 4(b) show the plot of the reciprocal of $h$ plotted as a function of $V_{D S}$ for the planar and MMC devices, respectively. Following step (3), the extracted values of $R_{T H}$, which is the slope of the best fit line for the planar and MMC devices, are $419 \mathrm{~K} / \mathrm{W}$ and $136 \mathrm{~K} / \mathrm{W}$, respectively. These values compare well with those given in Ref. 17. The $R_{T H}$ of the MMC device is only $\sim 32 \%$ that of the planar device, although its current density is more than twice that of the planar device. Multiplied to their respective effective gate widths, we obtained $42 \mathrm{~K}-\mathrm{mm} / \mathrm{W}$ and $4.8 \mathrm{~K}-\mathrm{mm} / \mathrm{W}$ values of $R_{T H}$ for the planar and MMC devices, respectively. Incidentally, to further confirm its repeatability, we perform the same $R_{T H}$ extraction method on another MMC device having a $W_{\text {top }}$ of $\sim 70 \mathrm{~nm}$ and 250 periods of mesatrench structures within the gate electrode width of $100 \mu \mathrm{m}$, giving an effective total gate width $W_{\text {total }}$ of $17.5 \mu \mathrm{m}$, with all other dimensions $\left(L_{G}, L_{G D}\right.$, and $\left.L_{G S}\right)$ equal to that of the earlier MMC device. We obtained an $R_{T H}$ value of $272 \mathrm{~K} / \mathrm{W}$, which when multiplied to the effective gate width $W_{\text {total }}=17.5 \mu \mathrm{m}$, translates to $4.8 \mathrm{~K}-\mathrm{mm} / \mathrm{W}$. Remarkably, this value is exactly equal to that of the earlier MMC device with $W_{\text {total }}$ of $35 \mu \mathrm{m}$. The lowest reported thermal resistance value of AlGaN/GaN HEMTs to date is $4.1 \mathrm{~K}-\mathrm{mm} / \mathrm{W}$ achieved by fabricating the device on low thermal resistivity but highly expensive single-crystal diamond (111) substrates. ${ }^{11}$ The value of $R_{T H}$ for our MMC device compares well to this record value considering that our devices are fabricated on more thermally resistive but cheaper and technologically mature sapphire substrates.

It can be argued that the lower $R_{T H}$ of the MMC device relative to that of the planar device is due to its slightly lower raw current and relatively wider access region. For a fairer comparison, we also fabricated an equivalent planar device having a $W_{\text {total }}=40 \mu \mathrm{m}$, which is almost equal to the $W_{\text {total }}$ of the MMC device whose $I_{D}-V_{D S}-T_{A}$ curves were shown in Fig. 4. For the equivalent planar device illustrated in Fig. 5(a), edges of the channel under the metal gate are etched so that a single channel island remains at the center having a total channel width $W_{\text {total }}$ almost equal to that of the MMC device. Both the MMC and equivalent planar devices have $L_{G}$ of $1 \mu \mathrm{m}, L_{G D}$ of $10 \mu \mathrm{m}$ and $L_{G S}$ of $2 \mu \mathrm{m}$, and device width $W$ of $200 \mu \mathrm{m}$. From Fig. 5(b), interestingly, even if it has a slightly larger $W_{\text {total }}$, the equivalent planar structure has only about $60 \%$ of the raw $I_{D}$ of the MMC device. Nevertheless, the equivalent planar device exhibited steeper negative slope of the $I_{D}-V_{D S}$ curves, suggesting more severe self-heating. Following the same $R_{T H}$ extraction method, we obtained a value of $474 \mathrm{~K} / \mathrm{W}$ for the equivalent planar device or $19 \mathrm{~K}$ $\mathrm{mm} / \mathrm{W}$ considering the effective width. These results support the earlier claim that the MMC device has significantly less thermal resistance than conventional devices with planar gate structures.

The reduced thermal resistance in MMC devices can be attributed to its unique structure under the metal gate. Relative to the conventional planar device, because of its higher impedance, the channel region of the MMC device 


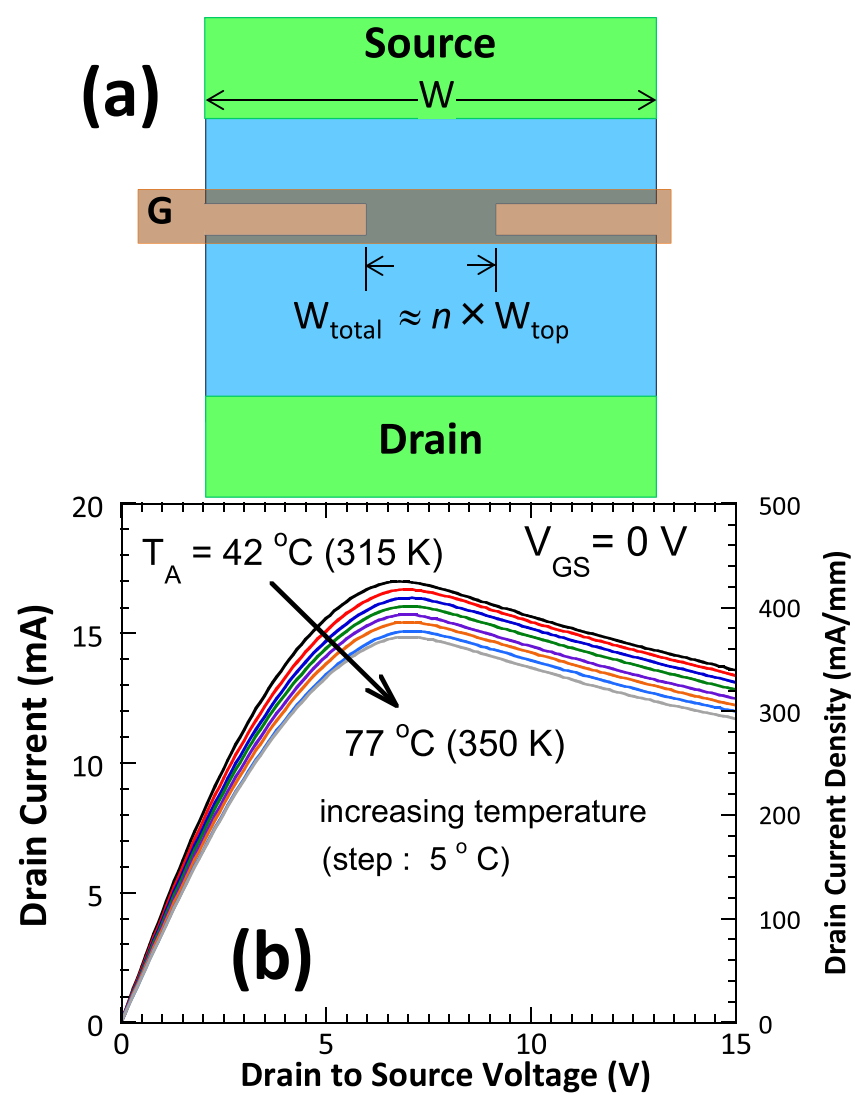

FIG. 5. (a) Schematic plan view of the equivalent planar device illustrating $W_{\text {total }}$ (b) $T_{A}$ dependence of $I_{D}-V_{D S}$ curves of the equivalent planar device with $W_{\text {total }}$ of $40 \mu \mathrm{m}$.

dissipates a greater percentage of the total power dissipation $P_{D}$. Also, as schematically illustrated in Fig. 6, the proximity of the "cold" GaN regions below the trenches, which serve as the heat spreader, to the "hot" GaN regions below the current carrying mesa channel structures and to the "hotspots" localized at the G-D edge ${ }^{4,10,26}$ gives high heat spreading ability to the MMC device. Particularly, the "hot" GaN regions are directly adjacent to "cold" GaN regions creating a large temperature gradient which drives heat to flow laterally. The heat can then be conducted towards the substrate or radiated to ambient. For the planar device, because of the absence of this mesa-trench structure, such lateral heat flow perpendicular to the direction of the current is substantially smaller. Moreover, the width of the "hot" mesa region $\left(W_{\text {top }}\right)$

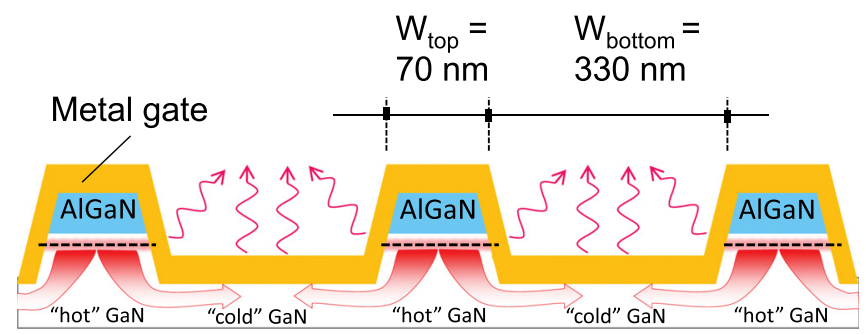

FIG. 6. Heat conduction away from the active mesa-channels schematic illustration (not drawn to scale). Regions of GaN buffer directly below the trenches are relatively cold compared to those regions directly below the active mesa-channels. The adjoining "cold" regions below the trenches can efficiently divert heat away from the mesa-channels and hotspots localized near the drain side of the gate edge. The heat is then radiated to ambient or conducted away towards the substrate. is very small typically more than four times smaller than that of "cold" GaN region $\left(W_{\text {bottom }}\right)$. This relative largeness of the heat spreading "cold" region, compared with the "hot" region, also plays a part in the high heat spreading ability of the MMC structure. These "cold" regions extend all the way down to the substrate, providing a parallel heat path through the substrate to ambient. In addition, the mesa side-walls and the "cold" GaN regions below the trenches facilitate heat radiation to ambient providing direct parallel thermal paths to ambient. Effectively, these parallel thermal resistances give the MMC device a substantially reduced thermal resistance compared to the conventional planar device. Our structure-based approach to thermal management is rather radical because it intends to spread the heat flow through the "cold" GaN regions which are several tens or hundreds of nanometer away from the source of heat. Conventional methods use heat spreaders which are few microns away from the heat source. ${ }^{27}$ Moreover, because of the low thermal resistivity of $\mathrm{GaN}$, it alleviates the effect of the high thermal resistivity of $\mathrm{AlGaN}$ barrier layer on the device thermal characteristics. ${ }^{28}$ Our approach is also compatible and can be used in combination with the conventional techniques such as using highly thermally conductive substrates and employing heat spreading layers. Another important implication of our results is that it can pave the way for the serious consideration of lithium gallate (LGO), which has only a latticemismatch of $0.19 \%$ with $\mathrm{GaN}$, as a substrate for fabricating low-defect GaN-based transistors. ${ }^{29,30}$ As LGO is thermally resistive, it requires front side cooling scheme which the MMC structure can offer.

In summary, we have demonstrated dramatic reduction of thermal resistance in AlGaN/GaN Multi-Mesa-Channel (MMC) HEMTs on sapphire substrates. Compared with the conventional planar device grown on the same chip, the MMC HEMT exhibits much less negative slope of the $I_{D^{-}}$ $V_{D S}$ curves at the saturation region, indicating excellent suppression of self-heating effect. Using a method proposed by Menozzi and co-workers, we have obtained a thermal resistance value of $4.8 \mathrm{~K}-\mathrm{mm} / \mathrm{W}$. This value compares well to 4.1 K-mm/W, which is the thermal resistance of $\mathrm{AlGaN} / \mathrm{GaN}$ HEMTs on expensive single crystal diamond substrates and is the lowest reported value in literature. These recent results strongly suggest that due its unique device structure, the MMC device can be a promising alternative for better thermal management of high-power AlGaN/GaN HEMTS.

\footnotetext{
${ }^{1}$ U. K. Mishra, L. Shen, T. E. Kazior, and Y. F. Wu, Proc. IEEE 96, 287 (2008).

${ }^{2}$ G. D. Via, J. G. Felbinger, J. Blevins, K. Chabak, G. Jessen, J. Gillespie, R. Fitch, A. Crespo, K. Sutherlin, B. Poling, S. Tetlak, R. Gilbert, T. Cooper, R. Baranyai, J. W. Pomeroy, M. Kuball, J. J. Maurer, and A. BarCohen, Phys. Status Solidi C 11, 871 (2014).

${ }^{3}$ H. Morkoc, Handbook of Nitride Semiconductors and Devices: GaNBased Optical and Electronic Devices (Wiley-VCH, 2008).

${ }^{4}$ M. Kuball, J. M. Hayes, M. J. Uren, T. Martin, J. C. H. Birbeck, R. S. Balmer, and B. T. Hughes, IEEE Electron Device Lett. 23, 7 (2002).

${ }^{5}$ J. Kuzmik, P. Javorka, A. Alam, M. Marso, M. Heuken, and P. Kordos, IEEE Trans. Electron Devices 49, 1496 (2002).

${ }^{6}$ J. Joh, J. A. del Alamo, U. Chowdhury, T. M. Chou, H. Q. Tserng, and J. L. Jimenez, IEEE Trans. Electron Devices 56, 2895 (2009).

${ }^{7}$ R. J. Trew, D. S. Green, and J. B. Shealy, IEEE Microw. Mag. 10, 116 (2009).

${ }^{8}$ W. L. Liu and A. A. Balandin, J. Appl. Phys. 97, 073710 (2005).
} 
${ }^{9}$ R. Gaska, Q. Chen, J. Yang, A. Osinsky, M. A. Khan, and M. S. Shur, IEEE Electron Device Lett. 18, 492 (1997).

${ }^{10}$ N. Killat, M. Montes, J. W. Pomeroy, T. Paskova, K. R. Evans, J. Leach, X. Li, U. Ozgur, H. Morkoc, K. D. Chabak, A. Crespo, J. K. Gillespie, R. Fitch, M. Kossler, D. E. Walker, M. Trejo, G. D. Via, J. D. Blevins, and M. Kuball, IEEE Electron Device Lett. 33, 366 (2012).

${ }^{11}$ K. Hirama, Y. Taniyasu, and M. Kasu, Appl. Phys. Lett. 98, 162112 (2011).

${ }^{12}$ G. J. Riedel, J. W. Pomeroy, K. P. Hilton, J. O. Maclean, D. J. Wallis, M. J. Uren, T. Martin, U. Forsberg, A. Lundskog, A. Kakanakova-Georgieva, G. Pozina, E. Janzen, R. Lossy, R. Pazirandeh, F. Brunner, J. Wurfl, and M. Kuball, IEEE Electron Device Lett. 30, 103 (2009).

${ }^{13}$ N. Tanaka, H. Takita, Y. Sumida, and T. Suzuki, Phys. Status Solidi C 5, 2972 (2008).

${ }^{14}$ Z. Yan, G. X. Liu, J. M. Khan, and A. A. Balandin, Nat. Commun. 3, 827 (2012).

${ }^{15}$ J. Sun, H. Fatima, A. Koudymov, A. Chitnis, X. Hu, H. M. Wang, J. Zhang, G. Simin, J. Yang, and A. A. Khan, IEEE Electron Device Lett. 24, 375 (2003).

${ }^{16}$ J. Das, H. Oprins, H. F. Ji, A. Sarua, W. Ruythooren, J. Derluyn, M. Kuball, M. Germain, and G. Borghs, IEEE Trans. Electron Devices 53, 2696 (2006).

${ }^{17}$ R. Menozzi, G. A. Umana-Membreno, B. D. Nener, G. Parish, G. Sozzi, L. Faraone, and U. K. Mishra, IEEE Trans. Device Mater. Reliab. 8, 255 (2008).

${ }^{18}$ K. Ohi and T. Hashizume, Jpn. J. Appl. Phys., Part 1 48, 081002 (2009).
${ }^{19}$ K. Ohi, J. T. Asubar, K. Nishiguchi, and T. Hashizume, IEEE Trans. Electron Devices 60, 2997 (2013).

${ }^{20}$ J. T. Asubar, K. Ohi, K. Nishiguchi, and T. Hashizume, Phys. Status Solidi C 11, 857 (2014).

${ }^{21}$ D. S. Lee, H. Wang, A. Hsu, M. Azize, O. Laboutin, Y. Cao, J. W. Johnson, E. Beam, A. Ketterson, M. L. Schuette, P. Saunier, and T. Palacios, IEEE Electron Device Lett. 34, 969 (2013).

${ }^{22}$ G. S. Simin, M. Islam, M. Gaevski, J. Y. Deng, R. Gaska, and M. S. Shur, IEEE Electron Device Lett. 35, 449 (2014).

${ }^{23}$ R. Menozzi and A. C. Kingswood, IEEE Trans. Device Mater. Reliab. 5, 515 (2005).

${ }^{24}$ R. Gaska, A. Osinsky, J. W. Yang, and M. S. Shur, IEEE Electron Device Lett. 19, 89 (1998).

${ }^{25}$ S. P. McAlister, J. A. Bardwell, S. Haffouz, and H. Tang, J. Vac. Sci. Technol. A 24, 624 (2006).

${ }^{26}$ Y. Ohno, M. Akita, S. Kishimoto, K. Maezawa, and T. Mizutani, Phys. Status Solidi C 0, 57 (2002).

${ }^{27}$ G. H. Jessen, J. K. Gillespie, G. D. Via, A. Crespo, D. Langley, J. Wasserbauer, F. Faili, D. Francis, D. Babic, F. Ejeckam, S. Guo, and I. Eliashevich, Tech. Dig. - Proc. IEEE Compd. Semicond. Integr. Circuit Symp. 2006, 271.

${ }^{28}$ C. Hodges, J. A. Calvo, S. Stoffels, D. Marcon, and M. Kuball, Appl. Phys. Lett. 103, 202108 (2013).

${ }^{29}$ R. Quay, Gallium Nitride Electronics (Springer-Verlag, 2008).

${ }^{30}$ A. Christensen, W. A. Doolittle, and S. Graham, IEEE Trans. Electron Devices 52, 1683 (2005). 